\title{
"Annals of Forest Science" takes a step further to enhance its impact!
}

\begin{abstract}
"Annals of Forest Science" is rooted in a long history of publishing forest science material, that began at the beginning of the 20th century as "Annales de l'Ecole Nationale des Eaux et Forêts". Various changes have of course been made to the journal to allow it to cope with the course of science and of the international scientific context. In particular, the journal switched to the predominant use of English, as the language for international scientific exchange. It changed its name several times, becoming "Annales des Sciences Forestières" during the 70s, and "Annals of Forest Science" end of the 90s. It also moved to a new publisher (EDP Sciences) and a different format during the last years. As a result, the journal still is active in 2005 and ranks among the best Journals in Forest Research.

The recent years have seen the start of many new Journals devoted to basic scientific disciplines (plant and animal physiology, biology, genetics, or genomics) or to crucial domains about environment or global change. Nevertheless, Annals of Forest Science, still aims to evolve as an efficient journal bridging several fields of importance for forests, namely tree biology, wood quality and ecology of forested ecosystems within a unique journal. In addition, is seeks to enhance its scientific excellency and is indexed in many large international publication data bases. The number of papers published in AFS increased to a large extent during the last years (it more than doubled!), and the published papers are now coming from all over the world, demonstrating the real international background of the journal.
\end{abstract}

The world of scientific publications is currently facing new challenges provided by the huge development of electronic technologies and of the world-wide-web. Indeed, these developments provide an opportunity for a much broader diffusion of knowledge and research results. Annals of Forest Science, and its publisher, EDP Sciences, already made an important effort to improve the on-line access to the journal, to have a cross referencing system linking the papers to other relevant information, and this effort will be continued. Moreover, AFS and EDP decided to have the pdf version of all papers freely available to everybody two years after the initial publication and in this respect contribute to the diffusion of the information.

We are now proposing to go a step further into this direction and to develop several new prospects for the journal. First, the management of the manuscripts will be fully electronic, and we soon will use a manuscript management system developed by EDP. The submission of manuscript is already electronic (see the new instructions to authors) and all information exchange between authors, editors and referees will be solely electronic. This should contribute to fasten the reviewing process and to reduce the delay before publication of the accepted papers.

Another evolution will be the development of an Open Access option, i.e., the possibility offered to authors to have their paper accessible freely (that is to colleagues and students that have not subscribed to the journal) immediately after publication. This should contribute to a significant increase of the impact of the published papers. This possibility will be opened at a very low charge to the authors who wish to use it or their institution (300 Euros). The editorial board of AFS wishes to conduct this experiment with the aim of enhancing the visibility and the impact of the journal. We will of course check after a few months what consequences it has on the financial balance of the Journal, and if this Open Access option really increased the impact of the Journal.

We hope, dear reader and dear author, that these changes in the management of the journal and in the access to the published information, will satisfy both those who wish to have an easy access to scientific results and those who want to have their research results made available to a large number of interested colleagues.

The editorial board of Annals of Forest Science 